Article

\title{
Chestnut Shells as Waste Material for Succinic Acid Production from Actinobacillus succinogenes $130 \mathrm{Z}$
}

\author{
Michela Ventrone ${ }^{1}$, Chiara Schiraldi $^{1}\left(\mathbb{D}\right.$, Giuseppe Squillaci $^{2}\left(\mathbb{D}\right.$, Alessandra Morana $^{2}(\mathbb{D}$ \\ and Donatella Cimini ${ }^{1, *}$ \\ 1 Section of Biotechnology, Medical Histology and Molecular Biology, Department of Experimental Medicine, \\ University of Campania L. Vanvitelli, Via de Crecchio 7, 80138 Naples, Italy; \\ michelaventrone87@gmail.com (M.V.); chiara.schiraldi@unicampania.it (C.S.) \\ 2 Research Institute on Terrestrial Ecosystems, National Research Council of Italy, Via Castellino 111, \\ 80131 Naples, Italy; giuseppe.squillaci@iret.cnr.it (G.S.); alessandra.morana@cnr.it (A.M.) \\ * Correspondence: donatella.cimini@unicampania.it; Tel.: +39-081-5667686
}

Received: 29 September 2020; Accepted: 4 November 2020; Published: 6 November 2020

\begin{abstract}
Currently, the full exploitation of waste materials for the production of value-added compounds is one of the potential solutions to lower costs and increase the sustainability of industrial processes. In this respect, the aim of this work was to evaluate the potential of chestnut shells (CSH) as substrate for the growth of Actinobacillus succinogenes 130Z, a natural producer of succinic acid that is a precursor of several bulk chemicals with diverse applications, such as bioplastics production. Hydrolysis of ammonia pretreated CSH in citrate buffer with the Cellic CTec2 enzyme mix was optimized and strain performance was studied in bottle experiments. Data showed co-consumption of citrate, glucose and xylose, which resulted in a change of the relative ratio of produced acids, providing an insight into the metabolism of $A$. succinogenes that was never described to date. Furthermore, high C:N ratios seems to have a favorable impact on succinic acid production by decreasing byproduct formation. Finally, yield and volumetric production rate of succinic acid were studied in controlled $2 \mathrm{~L}$ bioreactors demonstrating the potential use of $\mathrm{CSH}$ as renewable raw material.
\end{abstract}

Keywords: chestnut shell; Actinobacillus succinogenes; succinic acid; citric acid; waste biomass; byproduct reduction

\section{Introduction}

Increasing concerns regarding fossil fuel depletion and its impact on the environment, together with the growing establishment of "zero-waste" economy principles, currently put considerable emphasis on the development of industrial processes that recover and recycle waste materials to be converted into added value bio-products. This is particularly valid for wastes generated from food and food processing industries that can be used as raw materials for the set-up of sustainable biotechnological processes.

Chestnut shells (CSH) represent the main by-product of the industrial chestnut peeling process, and they were shown to have several applications as sources of antioxidants [1], as heavy metal adsorbents [2], and as potential phenol substitutes in the formulation of adhesives [3]. It is also interesting to evaluate the potential use of this waste biomass as a carbon source in biotechnological processes. However, although different methods for the pretreatment of $\mathrm{CSH}$ and the production of fermentable sugars were described in the literature [4,5], only few examples exist on its use as substrate for microbial growth $[5,6]$.

Succinic acid is a valuable product with numerous established applications in the biomedical and food fields, and furthermore it is used for the production of biodegradable plastics and 
as a precursor of many industrially important bulk chemicals (e.g., adipic acid, butanediol) [7]; in fact, its fossil-based production is recently being replaced by microbial fermentation processes. Several different microorganisms have been genetically engineered to produce succinic acid and among them are the natural producers Actinobacillus succinogenes, Mannheimia succiniciproduces and Basfia succiniciproducens [7-9]. Recently, a systems metabolic engineering approach based on malate dehydrogenase optimization and recombinant expression in $M$. succiniciproducens demonstrated the highest productivity of succinic acid reported to date [10]. The authors, in fact, obtained $21 \mathrm{~g} / \mathrm{L} \cdot \mathrm{h}$ of product in fed-batch fermentations on a chemically defined medium [10].

On the other hand, the reduction of process costs through the development of fermentation processes that use lignocellulosic feedstocks as raw materials, is one of the recent major targets for the biotechnological production of succinic acid. This approach is challenging due to the recalcitrance of the material and the release, during extraction of fermentable sugars, of compounds that can inhibit microbial growth. However, natural producer strains and also heterologous hosts, were tested on different agricultural and industrial renewable resources and diverse fermentation strategies, applied to lab and up to pre-pilot scale, were described [7,11-13].

A. succinogenes is one of the best natural producers of succinic acid, and due to its tolerance to furfural and hydroxymethylfurfural, that are released during the hydrolysis of lignocellulosic feedstocks [14], it is suitable for growing on sugars derived from agro-food waste biomasses.

Although in recent years a notable decrease in the average chestnut production has been observed due to climate changes and to the invasion of the gall wasp (Dryocosmus kuriphilus Y.), the Campania region is the major Italian chestnut supplier, with a high availability of waste from processing; therefore, the aim of the present work was to evaluate the growth of A. succinogenes $130 \mathrm{Z}$ and the production of succinic acid from ammonia pretreated chestnut shells, hydrolyzed with the Cellic CTec2 commercial enzyme mix that was previously used for the efficient hydrolysis of several lignocellulosic biomasses [15-17]. Growth experiments were conducted in bottles and in a controlled 2 L bioreactor to study the performance of $A$. succinogenes $130 Z$ also on concentrated hydrolysate. An insight into the induced metabolic shift of the strain in the presence of citrate and of increasing C:N ratios is also presented in the study.

\section{Materials and Methods}

\subsection{Biomass Pretreatment and Hydrolysis}

Chestnut shells, were pretreated with ammonia according to the protocol described by Maurelli and colleagues [4] to liberate cellulose and hemicellulose. Briefly, after size reduction in a bench top blender, dry biomass was incubated at $70{ }^{\circ} \mathrm{C}$ for $22 \mathrm{~h}$ in $10 \% v / v$ aqueous ammonia at a $5 \%$ w/v solid loading. The treated biomass was recovered by centrifugation and extensively washed with sodium citrate buffer to lower the $\mathrm{pH}$ to 5.2 .

The hydrolysis of pretreated $\mathrm{CSH}$ with the Cellic CTec2 (provided by Novozymes, Bagsvaerd, Denmark) was carried out at $50{ }^{\circ} \mathrm{C}$, with a concentration of pretreated biomass of $5 \%(w / v)$ in sodium citrate buffer $(5$ and $50 \mathrm{mM}) \mathrm{pH}$ 5.2. Preliminary experiments to identify the best operating conditions in terms of buffer composition and enzyme amount were conducted in a final volume of $5 \mathrm{~mL}$; the volume was scaled up to $1 \mathrm{~L}$ for preparative experiments. Enzymes were initially dosed at $0.3,0.6,1.2,1.5$ and $2 \mathrm{~g}$ enzyme per $\mathrm{g}$ of cellulose present in the substrate $(>1000 \mathrm{U} / \mathrm{g}$, $\mathrm{d}=1.195 \mathrm{~g} / \mathrm{mL})$. Experiments lasted $72 \mathrm{~h}$ and samples were withdrawn at different time intervals $(0,24$, 48 and $72 \mathrm{~h}$ ), cooled on ice and centrifuged at $12,000 \times \mathrm{g}$ for $30 \mathrm{~min}$ at $4{ }^{\circ} \mathrm{C}$. The supernatants were analyzed to quantify the amount of sugars released by high-performance liquid chromatography as described in Section 2.4. 
The conversion of cellulose and hemicellulose to glucose and xylose, respectively, as a percentage of their theoretical yields from the saccharification of chestnut shells, was calculated as follows [13]:

$$
\text { Cellulose or Hemicellulose conversion }(\%)=\frac{[\text { Glucose }] \text { or }[\text { Xylose }]}{[\text { Biomass }] \cdot F_{\text {cell }} \text { or } F_{\text {hcell }} \cdot 1.11 \text { or } 1.14} \cdot 100
$$

where [Glucose or Xylose] is the concentration of glucose and xylose in the hydrolysates $(\mathrm{g} / \mathrm{L})$; $[$ Biomass $]$ is the concentration of dry CSH used during the hydrolytic reaction $(\mathrm{g} / \mathrm{L}) ; F_{\text {cell }}$ and $F_{\text {hcell }}$ is the fraction of $\alpha$-cellulose (28.4) and hemicellulose (7.9) in the dry biomass (g/g), respectively [4]; 1.11 and 1.14 are the factors for the conversion of glucans to glucose and xylan to xylose, respectively [18].

The hydrolysis conditions used for all following experiments saw the use of $0.6 \mathrm{~g}$ of enzymes per $\mathrm{g}$ of cellulose and $24 \mathrm{~h}$ of incubation time.

\subsection{Small Scale Bottle Fermentation Experiments}

A. succinogenes $130 \mathrm{Z}$ used for all bottle experiments was purchased from the ATCC collection (ATCC 55618). Before each experiment, seed cultures of A. succinogenes $130 \mathrm{Z}$ were grown overnight $(\mathrm{o} / \mathrm{n})$ in the semi-defined medium $\mathrm{MH}$, at $37^{\circ} \mathrm{C}$ and $140 \mathrm{rpm}$, in a rotary shaker incubator (model Minitron, Infors, Bottmingen, Switzerland). The $\mathrm{MH}$ medium contained: $5 \mathrm{~g} / \mathrm{L}$ yeast extract, $10 \mathrm{~g} / \mathrm{L}$ neutralized soya peptone, $2 \mathrm{~g} / \mathrm{L}\left(\mathrm{NH}_{4}\right)_{2} \mathrm{SO}_{4}, 0.2 \mathrm{~g} / \mathrm{L} \mathrm{CaCl} \cdot \mathrm{H}_{2} \mathrm{O}, 0.2 \mathrm{~g} / \mathrm{L} \mathrm{MgCl}_{2} \cdot 6 \mathrm{H}_{2} \mathrm{O}, 2 \mathrm{~g} / \mathrm{L} \mathrm{NaCl}, 3 \mathrm{~g} / \mathrm{L} \mathrm{K}_{2} \mathrm{HPO}_{4}$, $10 \mathrm{~g} / \mathrm{L} \mathrm{MgCO} 3,1 \mathrm{mg} / \mathrm{L} \mathrm{Na} 2 \mathrm{~S} \cdot 9 \mathrm{H}_{2} \mathrm{O}$ as described in [19]. Pure glucose was added as carbon source for control experiments, whereas for evaluating growth on chestnut shells, the $\mathrm{MH}$ medium components, resuspended in $10 \%(v / v)$ of the final working volume, were supplemented with $90 \%(v / v)$ of CHS hydrolysate as specified in the following text. Small scale bottle fermentation experiments were performed by growing $A$. succinogenes in $0.1 \mathrm{~L}$ bottles (Pyrex) filled with $0.1 \mathrm{~L}$ of medium. The $\mathrm{pH}$ of the $\mathrm{MH}$ medium was buffered at $6.5 \pm 0.1$ before autoclaving with $6 \mathrm{M} \mathrm{HCl}$. The o/n pre-culture was diluted in the fresh medium to a starting $\mathrm{OD}_{600}$ of about $0.08 \pm 0.02$. The optical density was only measured when growing the strain on $\mathrm{MH}$ medium (without hydrolysate) due to the presence of solid residues in the $\mathrm{CSH}$ hydrolysate. Cultures were sparged with $\mathrm{CO}_{2}$ after inoculation and at each sampling point. Bottles were incubated at $37^{\circ} \mathrm{C}$ and $140 \mathrm{rpm}$.

In the first set of experiments, $90 \mathrm{~mL}$ of $\mathrm{CSH}$ enzymatic hydrolysate was added to $10 \mathrm{~mL}$ of a $10 \times$ stock solution of $\mathrm{MH}$ medium; in the second set of experiments, $90 \mathrm{~mL}$ of CSH enzymatic hydrolysate was added to $10 \mathrm{~mL}$ of a $10 \times$ stock solution of $\mathrm{MH}$ medium, and pure glucose was added to the $10 \times$ stock solution of MH medium to reach final concentrations of $12 \pm 1$ and $18 \pm 2 \mathrm{~g} / \mathrm{L}$ of glucose in the final solution. Control experiments in $\mathrm{MH}$ medium containing glucose $(7 \pm 1,12 \pm 1$ and $18 \pm 2 \mathrm{~g} / \mathrm{L})$ and xylose $(2.0 \pm 0.5 \mathrm{~g} / \mathrm{L})$ were also performed, as well as experiments on $\mathrm{MH}$ medium with the same concentrations of glucose and $\mathrm{MgCO}_{3}$, and in particular 20 and $50 \mathrm{~g} / \mathrm{L}$ (glucose: $\mathrm{MgCO}_{3}$ ratio equal to 1). Growth of $A$. succinogenes was also investigated on $\mathrm{MH}$ supplemented with $6 \mathrm{~g} / \mathrm{L}$ sodium citrate buffer. All bottle experiments were repeated at least three times, and data are reported as means \pm standard deviations.

\subsection{Batch Fermentations}

Batch experiments were run on a Biostat CT plus (3.2 L total volume) with a working volume of 2 L (Sartorius Stedim; Gottingen, Germany). A stock of the A. succinogenes $130 \mathrm{Z}$ working cell bank was inoculated in $0.25 \mathrm{~L}$ bottles on $\mathrm{MH}$ medium with glucose as $\mathrm{C}$-source. Once the strain reached the exponential phase, it was transferred in a Biostat $\mathrm{CT}$ plus reactor containing $\mathrm{MH}$ medium supplemented with CSH hydrolysate in order to have a starting glucose concentration of $6 \pm 1$ and $12 \pm 1 \mathrm{~g} / \mathrm{L}$, respectively, in the medium. In the latter case, the hydrolysate was lyophilized in a lyophilizer (Epsilon 2-6D, Christ, Osterode am Harz, Germany) o/n, and re-dissolved in distilled water to reach a 2 -fold concentration factor. Fermentations were carried out at $37^{\circ} \mathrm{C}$ with constant sparging of $\mathrm{CO}_{2}$ set to $0.1 \mathrm{vvm}$ and agitation speed of $150 \mathrm{rpm}$. A constant $\mathrm{pH}$ of 6.5 was maintained via 
automated addition of $25 \% v / v \mathrm{NH}_{4} \mathrm{OH}$ and $30 \% v / v \mathrm{H}_{2} \mathrm{SO}_{4}$. Broth samples were withdrawn during the course of the experiment from the reactors to determine substrate consumption and acids production. Batch fermentations were performed in duplicate.

\subsection{Analysis of Substrates and Products of Fermentation}

The supernatants obtained after centrifugation from broth samples collected during bottle and bioreactor experiments were ultrafiltered on $3 \mathrm{kDa}$ centricon devices (Millipore, Bedford, MA, USA) at $5000 \times g$. The flow through was analyzed for the determination of glucose, xylose and acids produced during growth by HPLC (UHPLC Dionex Ultimate 3000; Waltham, MA, USA, Thermofisher) equipped with a Resex ${ }^{\mathrm{TM}}$ RoA-organic acid H+ column (300 $\mathrm{mm} \times 7.8 \mathrm{~mm}$ ID, Phenomenex, Torrance, CA, USA). Analyses were performed at $40{ }^{\circ} \mathrm{C}$ with $0.1 \% v / v$ phosphoric acid in water as mobile phase at a flow rate of $0.8 \mathrm{~mL} / \mathrm{min}$. Detection was performed via UV absorbance at $200 \mathrm{~nm}$ and refraction index (Shodex RI-101 detector, Max auto step $5.1 \mathrm{~s}$, Temperature $32{ }^{\circ} \mathrm{C}$, Rise time $1 \mathrm{~s}$, Polarity plus, Record Range $512 \mu \mathrm{RIU}$, Integrator Range $500 \mu \mathrm{RIU} / \mathrm{UV})$.

\section{Results and Discussion}

\subsection{CSH Pretreatment and Hydrolysis}

Several renewable resources have been investigated for succinic acid production to date, to reduce process costs and develop sustainable processes, and, those that offer an alternative to food-based feed stocks are of particular interest. In the present work we evaluated chestnut shells as a potential source of fermentable sugars by combining a previously developed pretreatment method, based on aqueous ammonia soaking [4], to saccharification with the Cellic Ctec2 enzyme mix (Novozymes, Bagsvaerd, Denmark). In order to identify the most feasible operating conditions and the lowest enzyme dosage, increasing amounts of enzymes, ranging from 0.3 to $2 \mathrm{~g} / \mathrm{g}$ cellulose present in the sample, were tested. Results reported in Figure 1 indicate that a threshold concentration of glucose liberated was reached by adding $0.6 \mathrm{~g}$ enzyme/g cellulose (Figure 1a). Longer incubation times (from 24 to $72 \mathrm{~h}$ ) improved the glucose yield, however, this also decreased the overall reaction volumetric productivity from 0.26 to $0.10 \mathrm{gglu} / \mathrm{L} \cdot \mathrm{h}$. Xylose release was also analyzed as shown in Figure $1 \mathrm{~b}$ and a similar trend was observed.

a)

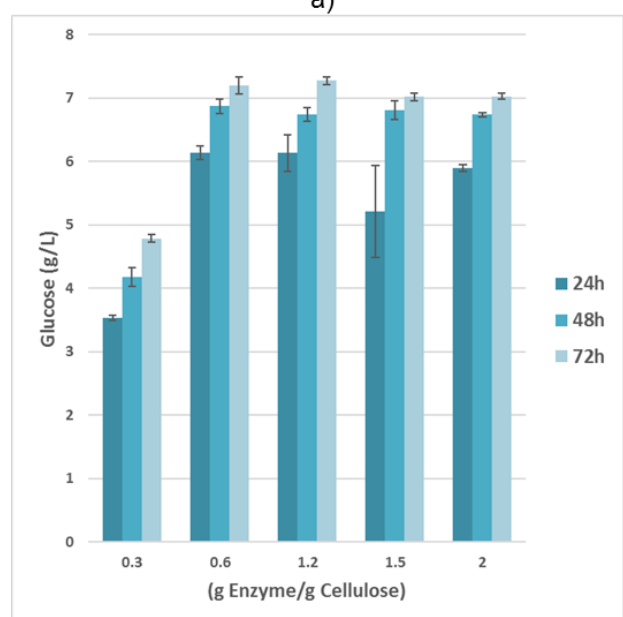

b)

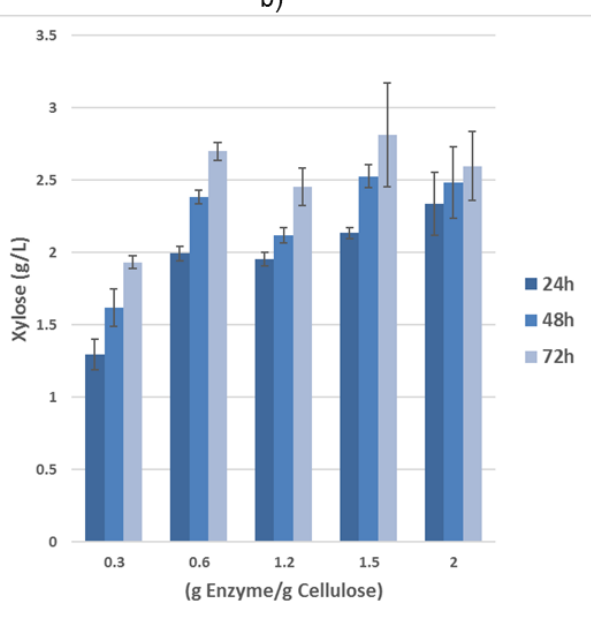

Figure 1. Enzymatic hydrolysis of pretreated chestnut shells with Cellic Ctec2. The reaction was conducted with a $5 \%(w / v)$ biomass load. Glucose (a) and xylose (b) release over time.

The obtained hydrolysis efficiencies are indicated in Table 1. 
Table 1. Efficiency of the saccharification of chestnut shells performed with $0.6 \mathrm{~g}$ enzyme/g cellulose on biomass pretreated with aqueous ammonia at $5 \%(w / v)$ loading. Efficiency was calculated with Equation (1) reported in the materials and methods section.

\begin{tabular}{ccccc}
\hline Incubation Time (h) & Glucose (g/L) & $\begin{array}{c}\text { Cellulose } \\
\text { Conversion (\%) }\end{array}$ & Xylose (g/L) & $\begin{array}{c}\text { Hemicellulose } \\
\text { Conversion (\%) }\end{array}$ \\
\hline 24 & $6.2 \pm 0.1$ & $52 \pm 1$ & $2.0 \pm 0.0$ & $53 \pm 1$ \\
48 & $6.9 \pm 0.1$ & $58 \pm 1$ & $2.4 \pm 0.0$ & $63 \pm 1$ \\
72 & $7.2 \pm 0.1$ & $61 \pm 1$ & $2.7 \pm 0.1$ & $71 \pm 2$ \\
\hline
\end{tabular}

By using an enzyme cocktail composed of Accellerase 1500, Accellerase BG and Accellerase XY, Maurelli and colleagues [4] obtained the highest yields of sugars released from CSH described to date, namely $67.8 \%$ glucose and $92.7 \%$ xylose after $72 \mathrm{~h}$ of incubation. The sugars release exhibited the same trend observed in our trials, as also Maurelli et al. [4] detected a high amount of glucose and xylose in the first $24 \mathrm{~h}(61 \%$ and $86 \%$ for glucose and xylose, respectively). In the present experiments by extending the incubation time up to $72 \mathrm{~h}$, the additional quantity of released sugars was even lower.

In this study, hydrolysis with only one enzymatic cocktail (Cellic Ctec2) on the same substrate resulted in a very similar glucose release whereas the amount of liberated xylose was lower. These data are interesting in the perspective of reducing costs of saccharification processes from pretreated waste CSH biomasses.

\subsection{Bottle Experiments on Pretreated and Hydrolysed Chestnut Shells}

In order to evaluate CSH hydrolysate as potential substrate for succinic acid production, the growth of $A$. succinogenes on this substrate was initially analyzed in bottle experiments. The final titer of succinic acid and the yield on consumed sugars obtained on CSH hydrolysate were only slightly lower compared to those observed on the control $\mathrm{MH}$ medium with similar initial concentrations of glucose and xylose (Figure 2).

a)

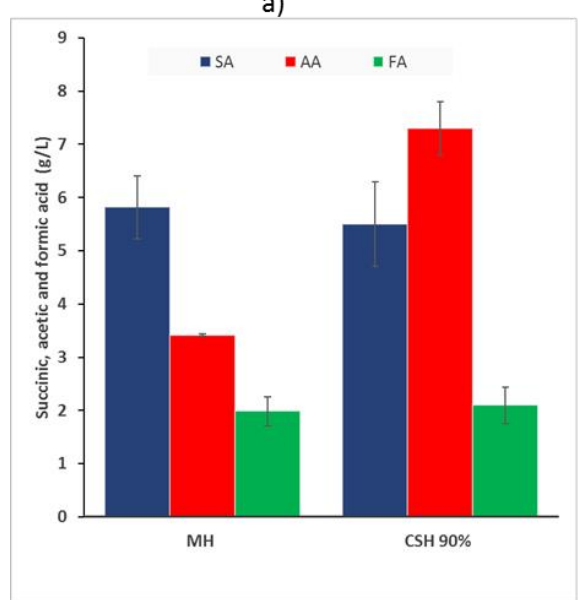

b)

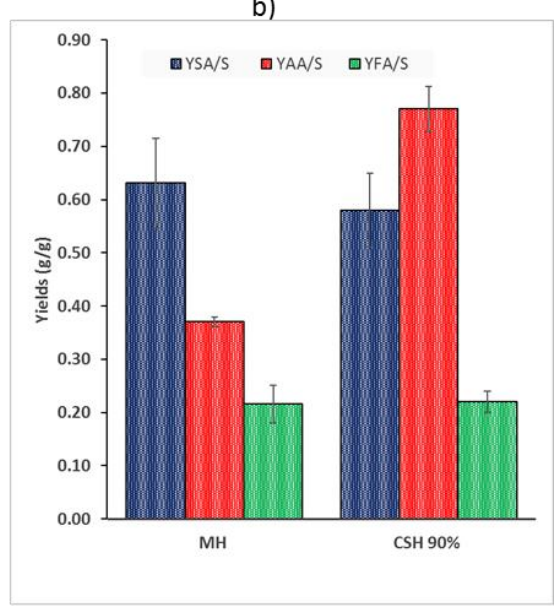

Figure 2. (a) Final concentrations of acids produced during growth of $A$. succinogenes in $0.1 \mathrm{~L}$ bottles and (b) yields. The strain was grown on the semidefined $\mathrm{MH}$ medium containing glucose $(7 \pm 1 \mathrm{~g} / \mathrm{L})$, and xylose $(2.0 \pm 0.5 \mathrm{~g} / \mathrm{L})$ as carbon sources, and on chestnut shells $(\mathrm{CSH})$ hydrolysate $(90 \% v / v)$. Data represent mean and standard deviation of at least 3 replicates. $\mathrm{Y}_{\mathrm{SA} / \mathrm{S}}, \mathrm{Y}_{\mathrm{AA} / \mathrm{S}}$ and $\mathrm{Y}_{\mathrm{FA} / \mathrm{S}}$ indicate the $g$ of succinic acid, acetic acid and formic acid, respectively, produced per $g$ of glucose and xylose consumed. SA, succinic acid; AA, acetic acid; FA, formic acid.

Interestingly, the presence of the hydrolysate in the medium strongly increased the titer of acetic acid shifting the acetic acid/succinic acid (AA/SA) ratio from about $0.59 \pm 0.06$ to $1.00 \pm 0.05(\mathrm{~g} / \mathrm{g})$. We also observed that sodium citrate, used as buffer for hydrolysis and therefore present in the CSH 
hydrolysate, was consumed from $A$. succinogenes as carbon source concurrently with glucose and xylose [20].

In order to better elucidate whether the observed change from the production of succinic to acetic acid could be due to the availability of citrate, the metabolism of which was never studied in A. succinogenes to date, control experiments were run on semi-defined medium (MH) with and without citrate supplementation. The co-consumption of glucose and citrate can be clearly observed in Figure 3.

a)

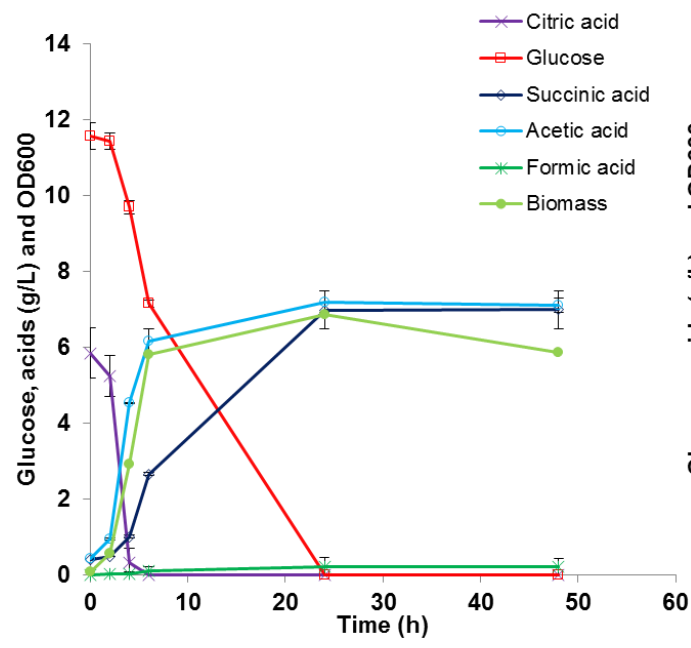

b)

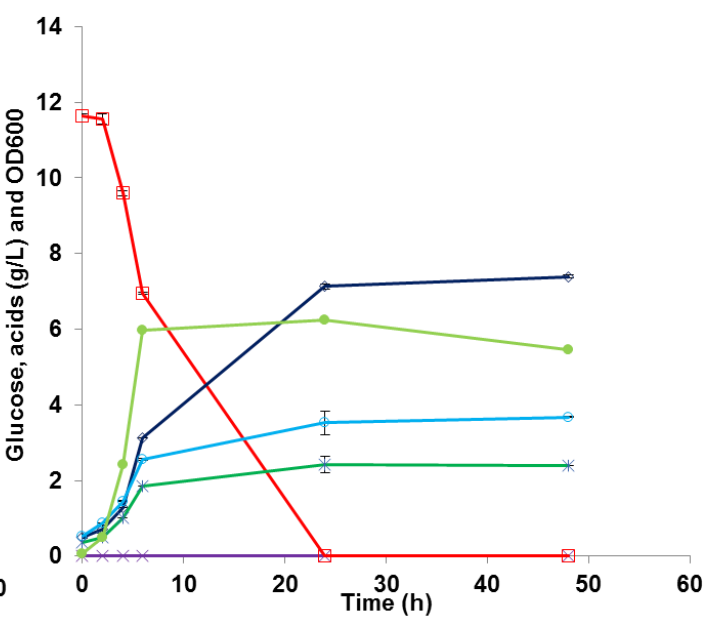

Figure 3. Growth of A. succinogenes in $0.1 \mathrm{~L}$ bottle experiments. Experiments were conducted on $\mathrm{MH}$ medium with (a) and without (b) citrate supplementation. Curves indicate consumption of glucose and citrate, and production of acids and biomass.

In particular, the volumetric consumption rate of glucose during the first $6 \mathrm{~h}$ of growth was similar in the two experiments (about $0.74 \mathrm{~g} / \mathrm{L} \cdot \mathrm{h}$ in Figure $3 \mathrm{a}, 0.78 \mathrm{~g} / \mathrm{L} \cdot \mathrm{h}$ in Figure $3 \mathrm{~b}$ ), and interestingly it was lower compared to that of citric acid $(1.3 \pm 0.07 \mathrm{~g} / \mathrm{L} \cdot \mathrm{h})$. Citric acid consumption was coupled to a 2.8- and 1.6-fold-higher production rate of acetic and formic acid, respectively, in the first $6 \mathrm{~h}$ of growth, whereas the volumetric productivity of succinic acid was slightly lower in the presence of citric acid. Moreover, as reported in Table 2 the yield of succinic acid on glucose was quite similar on the two media, while an almost $60 \%$ higher yield of acetic acid was obtained in the medium with citric acid supplementation.

Table 2. Yields of succinic, acetic and formic acid obtained by growing A. succinogenes $130 \mathrm{Z}$ on $\mathrm{MH}$ medium (with glucose as carbon source) and on $\mathrm{MH}$ medium plus citrate.

\begin{tabular}{cccc}
\hline & $\mathrm{Y}_{\mathrm{SA} / \mathrm{Gl}}(\mathrm{g} / \mathrm{g})$ & $\mathrm{Y}_{\mathrm{AA} / \mathrm{Gl}}(\mathrm{g} / \mathrm{g})$ & $\mathrm{Y}_{\mathrm{FA} / \mathrm{Gl}}(\mathrm{g} / \mathrm{g})$ \\
\hline $\mathrm{MH}$ & $0.64 \pm 0.01$ & $0.39 \pm 0.07$ & $0.27 \pm 0.05$ \\
$\mathrm{MH}+$ Citrate & $0.60 \pm 0.05$ & $0.61 \pm 0.01$ & $0.30 \pm 0.02$ \\
\hline
\end{tabular}

These results indicate that the presence of citrate in the medium does not significantly alter fluxes towards succinic acid; one potential explanation could be that citrate prompts the, at least partial, conversion of citrate itself to oxaloacetate and acetyl-CoA operated by citrate lyase, and the following conversion of acetyl-CoA to acetate. Moreover, the data also show that the glucose-to-citrate ratio influences the SA/AA ratio; in fact, the higher glucose/citrate ratio (1.99 \pm 0.16$)$ found in the experiments on $\mathrm{MH}$ medium, led to equal amounts of succinic and acetic acid, whereas on the medium containing the hydrolysate, in which the glucose/citrate was lower $(0.63 \pm 0.05)$ an inferior SA/AA of about $0.75 \pm 0.09$ was also observed. Joshi and colleagues [21], demonstrated that citrate lyase is not essential for fermentative growth of $A$. succinogenes on glucose, and therefore a possible strategy to avoid acetate accumulation could be the deletion of the cit operon. 
Growth experiments in $\mathrm{MH}$ medium with and without hydrolysate, and supplemented with up to $18 \pm 2 \mathrm{~g} / \mathrm{L}$ of glucose were also performed to simulate higher hydrolytic efficiencies that would be more suitable for a biotechnological process. However, in these growth conditions, incomplete sugar consumption was observed (Figure S1).

As shown in the figures, growth was strongly reduced or interrupted after $24 \mathrm{~h}$ of incubation. At this point, in fact, the carbonate was completely consumed (no solid residue could be observed in the bottles) and the $\mathrm{pH}$ decreased to 6 or slightly lower. Previously, Liu and collaborators reached high succinic acid concentrations in anaerobic bottle experiments by supplementing the medium with up to $60 \mathrm{~g} / \mathrm{L}$ of $\mathrm{MgCO}_{3}$ to avoid $\mathrm{pH}$ drop [22]. We therefore increased the concentration of $\mathrm{MgCO}_{3}$, proportionally with the carbon source $(20 \mathrm{~g} / \mathrm{L}$ glucose with $20 \mathrm{~g} / \mathrm{L} \mathrm{MgCO}$, and $50 \mathrm{~g} / \mathrm{L}$ of glucose with $50 \mathrm{~g} / \mathrm{L} \mathrm{MgCO}_{3}$ ) and this led to the consumption of all glucose and to a final pH equal to 6 or slightly higher (Table 3, Figure S2). Besides avoiding a pH drop below 6, the presence of higher $\mathrm{MgCO}_{3}$ concentrations might also be crucial in establishing and maintaining an anaerobic environment and thereby supporting growth. Furthermore, considering that the $\mathrm{CO}_{2}$ formed from the $\mathrm{MgCO}_{3}$ is also a carbon source for the production of SA, this is most likely also a metabolic requirement for SA production as well.

Table 3. Growth of A. succinogenes in bottles on MH medium with 10, 20 and $50 \mathrm{~g} / \mathrm{L}$ of glucose and $\mathrm{MgCO}_{3}$, respectively. Experiments were performed at least in duplicate. $\mathrm{pH}_{\text {fin }}$ indicates the $\mathrm{pH}$ measured when all the carbon source was consumed.

\begin{tabular}{|c|c|c|c|c|c|c|c|}
\hline & SA (g/L) & $\mathrm{Y}_{\mathrm{SA} / \mathrm{Gl}}(\mathrm{g} / \mathrm{g})$ & $\mathrm{Y}_{\mathrm{AA} / \mathrm{Gl}}(\mathrm{g} / \mathrm{g})$ & $\mathrm{Y}_{\mathrm{FA} / \mathrm{Gl}}(\mathrm{g} / \mathrm{g})$ & $Y_{x / G 1}(g / g)$ & $\mathrm{pH}_{\mathrm{fin}}$ & $\begin{array}{c}\text { Glucose } \\
\text { Exhaustion }\end{array}$ \\
\hline $\begin{array}{l}\text { Glucose } 10 \mathrm{~g} / \mathrm{L}, \\
\mathrm{MgCO} 310 \mathrm{~g} / \mathrm{L}\end{array}$ & $6.3 \pm 0.8$ & $0.64 \pm 0.01$ & $0.39 \pm 0.07$ & $0.27 \pm 0.05$ & $0.70 \pm 0.14$ & $6.0 \pm 0.1$ & $\begin{array}{c}\text { Between } 11 \\
\text { and } 24 \mathrm{~h}\end{array}$ \\
\hline $\begin{array}{l}\text { Glucose } 20 \mathrm{~g} / \mathrm{L} \\
\mathrm{MgCO}_{3} 20 \mathrm{~g} / \mathrm{L}\end{array}$ & $13.4 \pm 1.0$ & $0.76 \pm 0.05$ & $0.38 \pm 0.06$ & $0.24 \pm 0.05$ & $0.66 \pm 0.10$ & $6.2 \pm 0.2$ & $\begin{array}{c}\text { Between } 11 \\
\text { and } 24 \mathrm{~h}\end{array}$ \\
\hline $\begin{array}{l}\text { Glucose } 50 \mathrm{~g} / \mathrm{L}, \\
\mathrm{MgCO}_{3} 50 \mathrm{~g} / \mathrm{L}\end{array}$ & $33.9 \pm 1.9$ & $0.72 \pm 0.04$ & $0.14 \pm 0.01$ & $0.10 \pm 0.01$ & $0.28 \pm 0.01$ & $6.4 \pm 0.1$ & $\begin{array}{c}\text { Between } 55 \\
\text { and } 72 \mathrm{~h}\end{array}$ \\
\hline
\end{tabular}

It was also interesting to notice that higher glucose and $\mathrm{MgCO}_{3}$ concentrations (20 and $50 \mathrm{~g} / \mathrm{L}$ ) enhanced the yield of succinic acid; more interestingly, growth with $50 \mathrm{~g} / \mathrm{L}$ of glucose and $\mathrm{MgCO}_{3}$ resulted in a strongly reduced concentration of biomass and acid by-products (acetic and formic acid, Table 3). Considering that the glucose to $\mathrm{MgCO}_{3}$ ratio was constant in all conditions, the difference might be attributed to the carbon-to-nitrogen ratio. In fact, considering (i) an average bacterial biomass elemental composition equal to $\mathrm{CH}_{1.66} \mathrm{~N}_{0.20} \mathrm{O}_{0.27}-\mathrm{CH}_{2} \mathrm{~N}_{0.24} \mathrm{O}_{0.33}$ [23], (ii) the content of nitrogen in the $\mathrm{MH}$ medium, and (iii) an average $\mathrm{Y}_{\mathrm{x} / \mathrm{Gl}}$ of $0.68 \pm 0.11$ (calculated from experiments on 10 and $20 \mathrm{~g} / \mathrm{L}$ of glucose, Table 3) the moles of $\mathrm{N}$ needed to support the production of biomass in the presence of $50 \mathrm{~g} / \mathrm{L}$ of glucose might have been insufficient, thereby generating a condition of nitrogen limitation. However, interestingly although biomass production stopped after about $48 \mathrm{~h}$ of growth, glucose was still being mainly channeled to SA biosynthesis and less to the formation of acetic and formic acid (Table 3). Based on this, the establishment of nitrogen limitation might therefore be potentially advantageous in the further development of this process.

Moreover, only in these conditions, a concentration of about $3.9 \pm 0.5 \mathrm{~g} / \mathrm{L}$ of citric acid was also found in the media after $72 \mathrm{~h}$ of growth, indicating a change in the strains' metabolism.

\subsection{Batch Experiments in 2 L Bioreactors}

Since higher glucose/citrate ratios reduced acetic acid production, enzymatic hydrolysis experiments in $5 \mathrm{mM}$ citrate buffer (ten-times lower concentration compared to previous experiments) were performed. The results indicated that enzyme performance was not altered [20]. The resulting hydrolysate was used for batch experiments in controlled conditions on $2 \mathrm{~L}$ bioreactors. Experiments 
were conducted on $90 \%(v / v)$ CSH hydrolysate and on a two-fold concentrated sample (i.e., 180\% v/v) in order to test a higher initial sugar concentration (Figure 4).

a)

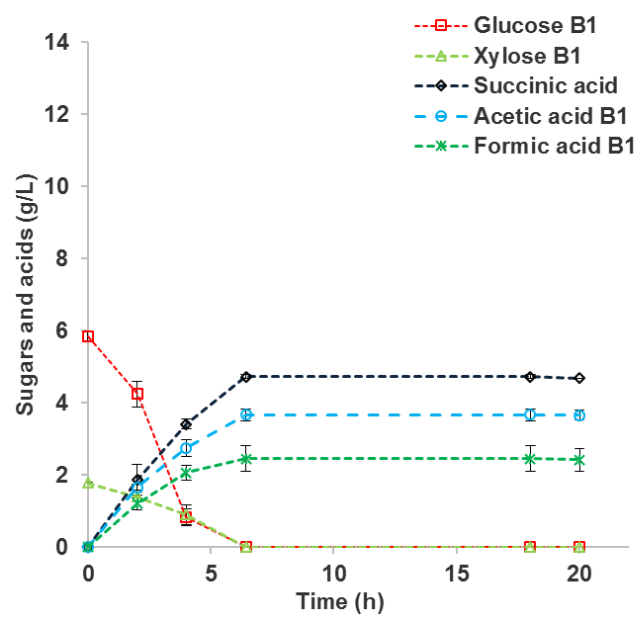

b)

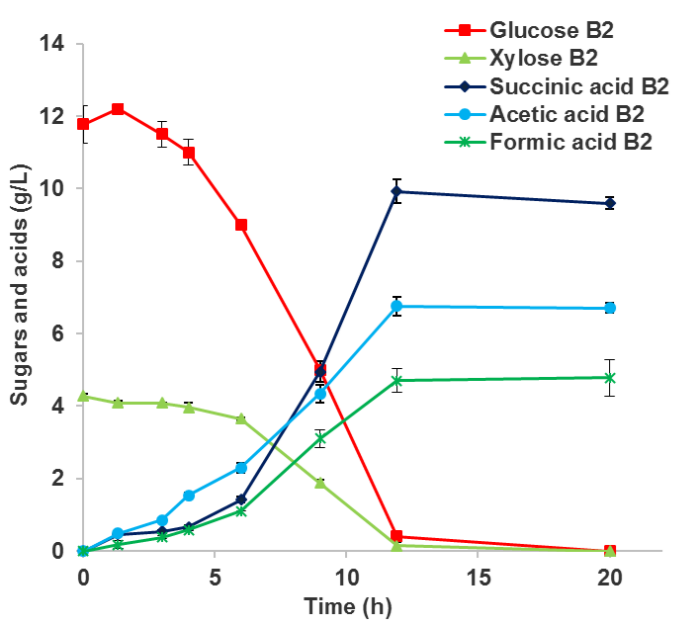

Figure 4. Batch experiments in $2 \mathrm{~L}$ bioreactors. A. succinogenes $130 \mathrm{Z}$ was grown at $37^{\circ} \mathrm{C}, \mathrm{pH} 6.5$ with constant sparging of $\mathrm{CO}_{2}$ on: (a) CSH hydrolysate $(90 \% v / v)$ and (b) concentrated CSH hydrolysate $(180 \% v / v)$.

In these conditions, the sugars were consumed after about 6 and $12 \mathrm{~h}$ respectively. A 2, 2.6 and 3.2 higher $r_{G l}, r_{X y l}$ and $r_{S A}$, respectively, were observed on $90 \%(v / v)$ CSH hydrolysate, compared to the concentrated medium (in the first $6 \mathrm{~h}$ of growth), thereby indicating a longer lag phase in the concentrated hydrolysate; however, the overall process productivity improved in the presence of higher glucose and xylose concentrations, resulting in a $15 \%$ higher $\mathrm{r}_{\mathrm{SA}}$ in these conditions. Compared to previously described bottle experiments, the strain demonstrated an improved productivity, and the production of up to about $10 \mathrm{~g} / \mathrm{L}$ of succinic acid, corresponding to an $\mathrm{r}_{\mathrm{SA}}$ of about $0.76 \pm 0.03 \mathrm{~g} / \mathrm{L} \cdot \mathrm{h}$. The average yield of succinic acid in batch was of about $0.62 \pm 0.02 \mathrm{~g} / \mathrm{g}$, which was very similar on the concentrated and not concentrated hydrolysate.

Several industrial and agricultural wastes were used for SA production in different fermentation conditions, and the results in terms of productivity and yield spanned from 0.31 to $1.74 \mathrm{~g} / \mathrm{L} \cdot \mathrm{h}$ and from 0.43 to $1.23 \mathrm{~g} / \mathrm{g}$, respectively $[7,24]$. In particular batch and fed-batch processes, and also repeated batch processes on immobilized $A$. succinogenes cells were used to exploit diverse agricultural wastes such as the more common corn and cotton stalk or sugar bagasse, and also traditional renewable sources such as the Mexican Agave tequilana and the Japanese sake lees [7]. Bioelectrochemical bioreactors were applied to anaerobic fed-batch growth of $A$. succinogenes on cane molasses yielding $84 \mathrm{~g} / \mathrm{L}$ of succinic acid and a surprisingly high productivity of $1.74 \mathrm{~g} / \mathrm{L} \cdot \mathrm{h}$ of product [25]. Focusing on inexpensive and locally abundant waste carbon sources $\mathrm{Li}$ and colleagues exploited simple anaerobic batch processes that resulted in about $16 \mathrm{~g} / \mathrm{L}$ of succinic acid and in one of the highest reported yields per $\mathrm{g}$ of consumed glucose [26]. Finally, Patsalou and coworkers valorized hydrolyzed citrus peel in $0.1 \mathrm{~L}$ bottle batch fermentations with continuous $\mathrm{CO}_{2}$ sparging producing about $8 \mathrm{~g} / \mathrm{L}$ of succinic acid with a yield of $0.7 \mathrm{~g}$ per $\mathrm{g}$ of total consumed sugars [27].

The data produced here are therefore in line with the previous literature.

\section{Conclusions}

With the aim of promoting the circular use of biomass and the valorization of food residues and waste, this study indicates that chestnut shells are a potentially useful waste substrate for the production of succinic acid from A. succinogenes 130Z. Moreover, the improvement of biomass pretreatment and hydrolysis, and the concentration of the recovered sugars could strongly improve 
succinic acid production titers. The latter might also be improved by higher $\mathrm{C}: \mathrm{N}$ ratios and/or $\mathrm{N}$ limitation, that promotes SA biosynthesis to the detriment of biomass and other acid by-products. From an industrial point of view, reducing by-product formation is a potential target to increase the economic viability of the process since the presence of contaminating acids adversely affects the recovery of succinic acid; succinic acid purification, in fact, accounts for $60-70 \%$ of the total process production costs [28-31].

Supplementary Materials: The following are available online at http://www.mdpi.com/2311-5637/6/4/105/s1. Figure S1: Growth of $A$. succinogenes in $0.1 \mathrm{~L}$ bottle experiments. Experiments were conducted on MH medium (a) and (c), and on $90 \% v / v$ CSH hydrolysate supplemented with glucose up to $12 \pm 1$ and $18 \pm 2 \mathrm{~g} / \mathrm{L}$. Curves indicate consumption of glucose and citrate, production of acids and $\mathrm{pH}$ measurements during the cultivation. Figure S2: Growth of $A$. succinogenes in $0.1 \mathrm{~L}$ bottle experiments. Experiments were conducted on $\mathrm{MH}$ medium with about: (a) $50 \mathrm{~g} / \mathrm{L}$ of glucose and $50 \mathrm{~g} / \mathrm{L}$ of $\mathrm{MgCO}_{3}$, (b) $20 \mathrm{~g} / \mathrm{L}$ of glucose and $20 \mathrm{~g} / \mathrm{L}$ of $\mathrm{MgCO}_{3}$ and (c) $10 \mathrm{~g} / \mathrm{L}$ of glucose and $10 \mathrm{~g} / \mathrm{L}$ of $\mathrm{MgCO}_{3}$. Curves indicate consumption of glucose and production of acids and biomass during the cultivation.

Author Contributions: D.C. and C.S. conceived the study; D.C. drafted the manuscript and conducted bioreactor experiments; M.V. conducted pretreatment, hydrolysis, bottle and bioreactor experiments; G.S. and A.M. conducted preliminary pretreatment experiments; A.M. and C.S. provided useful comments on the manuscript draft. All authors have read and agreed to the published version of the manuscript.

Funding: This research received no external funding.

Acknowledgments: We kindly thank Novozymes (Denmark) for providing the Cellic Ctec2 enzymes used for all hydrolytic assays; chestnut shells were kindly provided by a food factory located in the Campania region.

Conflicts of Interest: The authors declare no conflict of interest.

\section{References}

1. Braga, N.; Rodrigues, F.; Oliveira, M.B.P.P. Castanea sativa by-products: A review on added value and sustainable application. Nat. Prod. Res. 2015, 29, 1-18. [CrossRef]

2. Vázquez, G.; Fernández-Agulló, A.; Gómez-Castro, C.; Freire, M.S.; Antorrena, G.; González-Álvarez, J. Response surface optimization of antioxidants extraction from chestnut (Castanea sativa) bur. Ind. Crop. Prod. 2012, 35, 126-134. [CrossRef]

3. Vázquez, G.; González-Alvarez, J.; Santos, J.; Freire, M.S.; Antorrena, G. Evaluation of potential applications for chestnut (Castanea sativa) shell and eucalyptus (Eucalyptus globulus) bark extracts. Ind. Crop. Prod. 2009, 29, 364-370. [CrossRef]

4. Maurelli, L.; Ionata, E.; La Cara, F.; Morana, A. Chestnut Shell as Unexploited Source of Fermentable Sugars: Effect of Different Pretreatment Methods on Enzymatic Saccharification. Appl. Biochem. Biotechnol. 2013, 170, 1104-1118. [CrossRef] [PubMed]

5. Morana, A.; Squillaci, G.; Paixão, S.; Alves, L.; Cara, F.; Moura, P. Development of an Energy Biorefinery Model for Chestnut (Castanea sativa Mill.) Shells. Energies 2017, 10, 1504. [CrossRef]

6. Eryasar, K.; Karasu-Yalcin, S. Evaluation of some lignocellulosic byproducts of food industry for microbial xylitol production by Candida tropicalis. 3 Biotech 2016, 6, 202-209. [CrossRef]

7. Dessie, W.; Xin, F.; Zhang, W.; Jiang, Y.; Wu, H.; Ma, J.; Jiang, M. Opportunities, challenges, and future perspectives of succinic acid production by Actinobacillus succinogenes. Appl. Microbiol. Biotechnol. 2018, 102, 9893-9910. [CrossRef] [PubMed]

8. $\quad$ Lee, J.W.; Yi, J.; Kim, T.Y.; Choi, S.; Ahn, J.H.; Song, H.; Lee, M.H.; Lee, S.Y. Homo-succinic acid production by metabolically engineered Mannheimia succiniciproducens. Metab. Eng. 2016, 38, 409-417. [CrossRef]

9. Lange, A.; Becker, D.J.; Schulze, D.; Cahoreau, E.; Portais, J.; Haefner, S.; Schröder, H.; Krawczyk, J.; Zelder, O.; Wittmann, C. Bio-based succinate from sucrose: High-resolution $13 \mathrm{C}$ metabolic flux analysis and metabolic engineering of the rumen bacterium Basfia succiniciproducens. Metab. Eng. 2017, 44, 198-212. [CrossRef]

10. Ahn, J.H.; Seo, H.; Park, W.; Seok, J.; Lee, J.A.; Kim, W.J.; Kim, G.B.; Kim, K.; Lee, S.Y. Enhanced succinic acid production by Mannheimia employing optimal malate dehydrogenase. Nat. Commun. 2020, 11. [CrossRef]

11. Akhtar, J.; Idris, A.; Abd, A.R. Recent advances in production of succinic acid from lignocellulosic biomass. Appl. Microbiol. Biotechnol. 2014, 98, 987-1000. [CrossRef] 
12. Salvachúa, D.; Smith, H.; John, P.C.S.; Mohagheghi, A.; Peterson, D.J.; Black, B.A.; Dowe, N.; Beckham, G.T. Succinic acid production from lignocellulosic hydrolysate by Basfia succiniciproducens. Bioresour. Technol. 2016, 214, 558-566. [CrossRef]

13. Cimini, D.; Zaccariello, L.; D’Ambrosio, S.; Lama, L.; Ruoppolo, G.; Pepe, O.; Faraco, V.; Schiraldi, C. Improved production of succinic acid from Basfia succiniciproducens growing on $A$. donax and process evaluation through material low analysis. Biotechnol. Biofuels 2019, 12, 22-35. [CrossRef]

14. Diaz, A.B.; Blandino, A.; Caro, I. Value added products from fermentation of sugars derived from agro-food residues. Trends Food Sci. Technol. 2018, 71, 52-64. [CrossRef]

15. Ju, X.; Bowden, M.; Engelhard, M.; Zhang, X. Investigating commercial cellulase performances toward specific biomass recalcitrance factors using reference substrates. Appl. Microbiol. Biotechnol. 2014, 98, 4409-4420. [CrossRef]

16. Rodrigues, A.C.; Haven, M.Ø.; Lindedam, J.; Felby, C.; Gama, M. Celluclast and Cellic ${ }^{\circledR}$ CTec2: Saccharification/fermentation of wheat straw, solid-liquid partition and potential of enzyme recycling by alkaline washing. Enzym. Microb. Technol. 2015, 79-80,70-77. [CrossRef]

17. Baral, P.; Jain, L.; Kurmi, A.K.; Kumar, V.; Agrawal, D. Augmented hydrolysis of acid pretreated sugarcane bagasse by PEG 6000 addition: A case study of Cellic CTec2 with recycling and reuse. Bioproc. Biosyst. Eng. 2020, 43, 473-482. [CrossRef]

18. Gunnarsson, I.B.; Kuglarz, M.; Karakashev, D.; Angelidaki, I. Thermochemical pretreatments for enhancing succinic acid production from industrial hemp (Cannabis sativa L.). Bioresour. Technol. 2015, 182, 58-66. [CrossRef]

19. Cimini, D.; Argenzio, O.; D’Ambrosio, S.; Lama, L.; Finore, I.; Finamore, R.; Pepe, O.; Faraco, V.; Schiraldi, C. Production of succinic acid from Basfia succiniciproducens up to the pilot scale from Arundo donax hydrolysate. Bioresour. Technol. 2016, 222, 355-360. [CrossRef]

20. Ventrone, M.; Schiraldi, C.; Cimini, D. Physiology of Actinobacillus succinogenes $130 \mathrm{Z}$ on MH and on chestnut shell hydrolysate. Unpublished work. 2020; Material not intended for publication.

21. Joshi, R.V.; Schindler, B.D.; McPherson, N.R.; Tiwari, K.; Vieille, C. Development of a Markerless Knockout Method for Actinobacillus succinogenes. Appl. Environ. Microbiol. 2014, 80, 3053-3061. [CrossRef]

22. Liu, Y.-P.; Zheng, P.; Sun, Z.-H.; Ni, Y.; Dong, J.-J.; Wei, P. Strategies of pH control and glucose-fed batch fermentation for production of succinic acid byActinobacillus succinogenes CGMCC1593. J. Chem. Technol. Biotechnol. 2008, 83, 722-729. [CrossRef]

23. Bailey, J.E.; Ollis, D.F. Biochemical Engineering Fundamentals, 2nd ed.; McGraw-Hill Chemical Engineering Series; McGraw-Hill: New York, NY, USA, 1986; ISBN 9780070032125.

24. Maslova, O.; Stepanov, N.; Senko, O.; Efremenko, E. Production of various organic acids from different renewable sources by immobilized cells in the regimes of separate hydrolysis and fermentation (SHF) and simultaneous saccharification and fermentation (SFF). Bioresour. Technol. 2019, 272, 1-9. [CrossRef]

25. Wang, Z.; Li, H.; Feng, J.; Zhang, A.; Ying, H.; He, X.; Jiang, M.; Chen, K.; Ouyang, P. Enhanced succinic acid production from polyacrylamide-pretreated cane molasses in microbial electrolysis cells. J. Chem. Technol. Biotechnol. 2018, 93, 855-860. [CrossRef]

26. Li, Q.; Yang, M.; Wang, D.; Li, W.; Wu, Y.; Zhang, Y.; Xing, J.; Su, Z. Efficient conversion of crop stalk wastes into succinic acid production by Actinobacillus succinogenes. Bioresour. Technol. 2010, 101, 3292-3294. [CrossRef]

27. Patsalou, M.; Menikea, K.K.; Makri, E.; Vasquez, M.I.; Drouza, C.; Koutinas, M. Development of a citrus peel-based biorefinery strategy for the production of succinic acid. J. Clean. Prod. 2017, 166, 706-716. [CrossRef]

28. Lee, P.C.; Lee, W.G.; Lee, S.Y.; Chang, H.N. Effects of medium components on the growth of Anaerobiospirillum succiniciproducens and succinic acid production. Process. Biochem. 1999, 35, 49-55. [CrossRef]

29. Lee, P.C.; Lee, W.G.; Lee, S.Y.; Chang, H.N. Succinic acid production with reduced by-product formation in the fermentation of Anaerobiospirillum succiniciproducens using glycerol as a carbon source. Biotechnol. Bioeng. 2001, 72, 41-48. [CrossRef] 
30. Baniel, A.M.; Eyal, A.M. Citric Acid Extraction. U.S. Patent 5,426,220, 20 June 1995.

31. Zhang, W.; Yang, Q.; Wu, M.; Liu, H.; Zhou, J.; Dong, W.; Ma, J.; Jiang, M.; Xin, F. Metabolic Regulation of Organic Acid Biosynthesis in Actinobacillus succinogenes. Front. Bioeng. Biotechnol. 2019, 7, $216-226$. [CrossRef]

Publisher's Note: MDPI stays neutral with regard to jurisdictional claims in published maps and institutional affiliations.

(C) 2020 by the authors. Licensee MDPI, Basel, Switzerland. This article is an open access article distributed under the terms and conditions of the Creative Commons Attribution (CC BY) license (http://creativecommons.org/licenses/by/4.0/). 